OPEN ACCESS

Edited by:

Davide Gibellini,

University of Bologna, Italy

Reviewed by:

Sheik Pran Babu Sardar Pasha,

University of California, Davis,

United States

Miodrag J. Colic

Institute for the Application of Nuclear

Energy (INEP), Serbia

${ }^{*}$ Correspondence:

Xuefen L

zylxf@zju.edu.cn

Weilin Wang

wam@zju.edu.cn

${ }^{t}$ These authors have contributed equally to this work

Specialty section:

This article was submitted to Molecular Medicine,

a section of the journal

Frontiers in Cell and Developmental

Biology

Received: 07 October 2020

Accepted: 19 February 2021

Published: 11 March 2021

Citation:

Li X, Liu X and Wang W (2021)

IL-35: A Novel Immunomodulator in

Hepatitis B Virus-Related

Liver Diseases.

Front. Cell Dev. Biol. 9:614847.

doi: 10.3389/fcell.2021.614847

\title{
IL-35: A Novel Immunomodulator in Hepatitis B Virus-Related Liver Diseases
}

\begin{abstract}
Xuefen $\mathrm{Li}^{1 * t}$, Xia $\mathrm{Li}^{2+}$ and Weilin Wang ${ }^{3 *}$
${ }^{1}$ Key Laboratory of Clinical In Vitro Diagnostic Techniques of Zhejiang Province, Department of Laboratory Medicine, The First Affiliated Hospital, Zhejiang University School of Medicine, Hangzhou, China, ${ }^{2}$ Hangzhou Global Scientific and Technological Innovation Center, Zhejiang University, Hangzhou, China, ${ }^{3}$ Key Laboratory of Precision Diagnosis and Treatment for Hepatobiliary and Pancreatic Tumor of Zhejiang Province, Division of Hepatobiliary and Pancreatic Surgery, Department of Surgery, Clinical Research Center of Hepatobiliary and Pancreatic Diseases of Zhejiang Province, The Second Affiliated Hospital, Zhejiang University School of Medicine, Hangzhou, China
\end{abstract}

Chronic hepatitis B virus (HBV) infection is a risk factor for liver cirrhosis (LC) and hepatocellular carcinoma (HCC), however, little is known about the mechanisms involved in the progression of HBV-related diseases. It has been well acknowledged that host immune response was closely related to the clinical outcomes of patients with HBV infection. As the factors closely related to the immunomodulatory process, cytokines are crucial in the cell-cell communication and the host responses to HBV infection. Recently, a newly discovered cytokine, designated as interleukin-35 (IL-35), has been proved to be essential for the progression of chronic HBV infection, the development of cirrhosis, the transformation of cirrhosis to HCC, and the metastasis of HCC. Specifically, it showed various biological activities such as inhibiting the HBV-specific cytotoxic T lymphocyte (CTL) proliferation and cytotoxicity, deactivating the immature effector T-cells (Teffs), as well as delaying the proliferation of dendritic cells. It regulated the immune responses by acting as a "brake" on the activation of Teffs, which subsequently played important roles in the pathogenesis of various inflammatory diseases and malignancies. In this review, we focused on the most recent data on the relationship between IL-35 and chronic HBV infection, LC and HCC.

\footnotetext{
Keywords: chronic hepatitis B, interleukin-35, cytotoxic T lymphocytes, induced regulatory T-cells, immunopathology
}

\section{INTRODUCTION}

Hepatitis B virus (HBV) infection is still a threat to health worldwide causing chronic infection among 250 million individuals (Lee and Banini, 2019). Patients with HBV infection may develop hepatic failure, liver cirrhosis (LC), and primary hepatocellular carcinoma (HCC), resulting in a death toll of more than 1 million annually (Polaris Observatory Collaborators, 2018; Lee and Banini, 2019). The pathogenesis of HBV infection is rather complicated, which is influenced by several factors including HBV genotype, viral variation and replication. In addition, host factors (e.g., sex, age, and immune status) and other exogenous factors (e.g., hepatitis viral co-infection and alcoholism) were also reported to be involved (Tong et al., 2010; Tang et al., 2018; Terrault et al., 2018; Vlachogiannakos and Papatheodoridis, 2018). Therefore, various manifestations of HBV 
infection can be seen clinically at different stages (Table 1). $\mathrm{HBV}$ is infected through person-to-person transmission at birth or after birth. Although the vaccines against HBV have been developed in the 1980 s, about $1 / 3$ of the population worldwide still showed a previous or existing HBV infection in serological tests (World Health Organization, 2013). Globally, viral hepatitis caused 1.34 million deaths in 2015. This result is similar to tuberculosis deaths (1.37 million) and is higher than HIV infections (1.06 million) and malaria (0.44 million). About 96\% of these people died from complications of chronic hepatitis and most of them (66\%) were diagnosed with chronic hepatitis caused by HBV. It was recognized as the disease with the highest burden by the WHO Western Pacific region (which includes 37 countries) in 2016 (World Health Organization, 2017; Seto et al., 2018).

To date, the pathogenesis of HBV infection is still not well defined. As is known to all, persistent HBV infection has been acknowledged to be closely associated with inadequate immune responses. Both innate and adaptive immunity were reported to be involved in anti-HBV immune response. During early stage of virus infection, innate sensing of viruses can occur through Toll-like receptors (TLRs) and cytosolic sensors that recognize viral DNA and RNA, then transmit a warning message to initiate downstream signals and activate effector components. In the later phase, antigen-presenting cells (APCs), including macrophages and dendritic cells (DCs), initialize the virusspecific adaptive immunity characterized by activation of $\mathrm{T}$ helper (Th) lymphocytes and secretion of various cytokines, which then mobilize the $\mathrm{CD}^{+}$cytotoxic T lymphocytes (CTLs) to kill the HBV-infected hepatocytes (Bertoletti and Gehring, 2006). Previous work showed that cell-mediated immunity is critical for clearance of HBV infection, in particular, robust and multiple epitope-specific $\mathrm{CD}^{+} \mathrm{T}$ cell responses are necessary for the spontaneous resolution of HBV infection (Thimme et al., 2003). Moreover, HBV-specific CD $4^{+} \mathrm{T}$ cells are also important in determining the outcome of acute HBV infection, as shown in a chimpanzee study that the depletion of $\mathrm{CD} 4^{+} \mathrm{T}$ cells abrogated the function of $\mathrm{CD}^{+} \mathrm{T}$ cells and resulted in chronic HBV infection (Asabe et al., 2009). In addition to T-cell responses, neutralizing antibodies produced by $\mathrm{B}$ cells are believed to play an integral role in of HBV detection and resolution. Unlike the adaptive immune system, the innate lymphoid cells (ILCs) mainly localized at mucosal surfaces acting as sentinel cells, where release of their cytokine suite inhibits establishment and spread of HBV virus infection (Yang et al., 2015). Importantly, there is growing evidence that cytokine-mediated immune responses play an important role in determining clinical outcomes during $\mathrm{HBV}$ viral control and virus-induced hepatic injury (Dandri and Locarnini, 2012; Seetharam et al., 2014; Li et al., 2016).

Interleukin (IL)-35 is a newly identified cytokine of the IL12 family and a potent immunosuppressive cytokine secreted by regulatory $\mathrm{T}$ (Treg) cells and the regulatory $\mathrm{B}$ (Breg) cells (Xiang and Xie, 2015). IL-35 and iTr35 cells develop a positive feedback loop to interact with each other, as $i \operatorname{Tr} 35$ cells generation can be induced by IL-35, while more IL-35 is further secreted by iTr 35 cells (Collison et al., 2010). Like transforming growth factor$\beta$ (TGF- $\beta$ ) and IL-10, IL-35 can also induce the development of induced regulatory $\mathrm{T}$ cell (iTreg) population (Collison et al., 2007). Moreover, IL-35 stimulation increased the inhibitory function of $\mathrm{CD} 4^{+} \mathrm{CD} 25^{+} \mathrm{CD} 127^{\mathrm{dim} /-}$ Tregs by reducing cellular proliferation and enhancing IL-35/IL-10 productions (Mitani et al., 2015; Shi et al., 2015). Thus, the current researches suggested that the elevated proportion of Tregs might be the major source of IL-35 enhancement in the serum of patients with CHB. Besides, IL-35 also induces Breg cells formation in vivo and promotes their conversion to a unique Breg subset that produces IL-35 (IL-35+ Breg) (Wang et al., 2014), and inhibit the proliferation and function of effector T-cells (Teffs) (Collison et al., 2007; Collison et al., 2010). A novel immunosuppresive subset named $\mathrm{CD}^{+}$Tregs were reported in both human and mice, exerting immunoregulatory function through secreting cytokines (Flippe et al., 2019). IL-35 has also been described as expressed and playing a suppressive role for tumor-associated $\mathrm{CD}^{+}{ }^{+}$Tregs (Olson et al., 2012; Zhang et al., 2019). Although very few papers were published on $\mathrm{CD}^{+}$Tregs function in HBV infection, based on the anti-inflammation role of $\mathrm{CD}^{+}$ Tregs in human disease (Vuddamalay and van Meerwijk, 2017), we hypothesize that IL-35 secreted by $\mathrm{CD} 8^{+}$Tregs in CHB patients may similarly contributed to immune tolerance and exhaustion state of CTLs, therefore, targeting IL-35 secreted $\mathrm{CD}^{+}$Tregs may provide peculiar thought for treatment of HBV infection. In conclusion, IL-35 can induce the generation of iTr35, Bregs and possibly CD8 ${ }^{+}$Tregs, which function as an immunosuppressive factor in immune mediated progression of chronic hepatitis $B$.

The effect of IL-35 on pro-inflammatory cytokines were also reported to be involved in the pathogenesis of HBV. For instance, IL-35 stimulation notably reduced concentrations of interferongamma (IFN- $\gamma$ ), IL-1 $\beta$, IL- 6 , and IL-8 produced by PBMCs, indicating IL-35 inhibited cytokines-induced antiviral immunity to HBV. Furthermore, the reduction of pro-inflammatory cytokine secretion in HBsAg and IL-35 co-stimulated PBMCs was accompanied by the decreased phosphorylation of STAT1 in comparison of HBsAg stimulation only group (Shao et al., 2017). Previous studies demonstrated that IL-35 showed inhibitory effects on the HBV-specific CTL response, which affected HBV clearance and modulated the pathogenesis of HCC (Li et al., 2015; Xiang and Xie, 2015; Xue et al., 2019). To our best knowledge, although more researches are exploring the role of IL-35 in human disease, few studies have been focused on the roles of IL35 in HBV infection. In this review, we summarized the possible immunoregulatory roles of IL-35 in the pathogenesis of CHB, LC and the hepatocarcinogenesis related with HBV infection. It contributed to the proposal of potential strategies for reversing exhaustion of $\mathrm{T}$ cells and the treatment programs of $\mathrm{CHB}$.

\section{BIOLOGICAL PROPERTIES OF IL-35}

IL-35 is a novel cytokine of the IL-12 family (Xiang and Xie, 2015). Each of IL-12 family members (e.g., IL-12, IL-23, IL-27, and IL-39) is a heterodimeric cytokine composed of $\alpha$ chain (i.e., p19, p28, and p35) and $\beta$ chain including p40 and Epstein-Barr virus-induced gene 3 [EBI3], which contain common subunits 
TABLE 1 | Clinical features of patients infected with HBV at different stages (Tong et al., 2010; Tang et al., 2018; Terrault et al., 2018; Vlachogiannakos and Papatheodoridis, 2018).

\begin{tabular}{|c|c|c|c|c|c|c|}
\hline \multirow[t]{2}{*}{ Clinical parameters } & \multicolumn{6}{|c|}{ Stages of HBV infection } \\
\hline & $\begin{array}{l}\text { Occult HBV } \\
\text { infection }\end{array}$ & Inactive carrier & $\begin{array}{l}\text { Acute self-limit } \\
\text { HBV infection }\end{array}$ & $\begin{array}{l}\text { Active chronic } \\
\text { HBV infection }\end{array}$ & HBV-related LC & HBV-related HCC \\
\hline \multirow[t]{5}{*}{ Virological markers } & HBsAg (-) & HBsAg $(+)$ & HBsAg (+) & HBsAg $(+)$ & HBsAg $(+)$ & HBsAg $(+)$ \\
\hline & $\mathrm{HBeAg}(-)$ & $\mathrm{HBeAg}(-)$ & $\mathrm{HBeAg}(+)$ & $\operatorname{HBeAg}( \pm)$ & $\mathrm{HBeAg}( \pm)$ & $\mathrm{HBeAg}( \pm)$ \\
\hline & Anti-HBc $(+)$ & Anti-HBc $( \pm)$ & Anti-HBc $( \pm)$ & Anti-HBc $( \pm)$ & Anti-HBc $( \pm)$ & Anti-HBc $( \pm)$ \\
\hline & Anti-HBe $( \pm)$ & Anti-HBe $( \pm)$ & Anti-HBe $( \pm)$ & Anti-HBe $( \pm)$ & Anti-HBe $( \pm)$ & Anti-HBe $( \pm)$ \\
\hline & HBV-DNA (+) & $\begin{array}{l}\text { HBV-DNA } \\
(<2,000 \mathrm{lU} / \mathrm{ml})\end{array}$ & HBV-DNA (+) & HBV-DNA (+) & HBV-DNA $( \pm)$ & HBV-DNA ( \pm$)$ \\
\hline Liver biochemistry & Normalization & Normalization & $\uparrow$ & $\uparrow \uparrow$ & Normalization/ $\uparrow$ & Normalization $/ \uparrow / \uparrow \uparrow$ \\
\hline Liver histopathology & No liver damage & $\begin{array}{l}\text { Low grade } \\
\text { inflammation }\end{array}$ & $\begin{array}{l}\text { Minimal or temple } \\
\text { liver damage }\end{array}$ & $\begin{array}{l}\text { Increased liver } \\
\text { damage }\end{array}$ & $\begin{array}{l}\text { Increased liver } \\
\text { damage }\end{array}$ & $\begin{array}{l}\text { Increased liver } \\
\text { damage }\end{array}$ \\
\hline Antiviral therapy & No & No & No & Yes & Yes & Yes \\
\hline
\end{tabular}

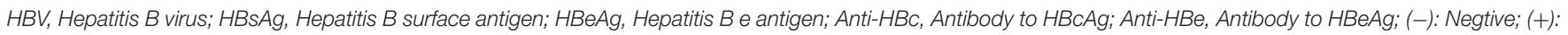
Positive; ( \pm ): Positive or Negative; $\uparrow:$ Increased; $\uparrow \uparrow:$ Significantly increased.

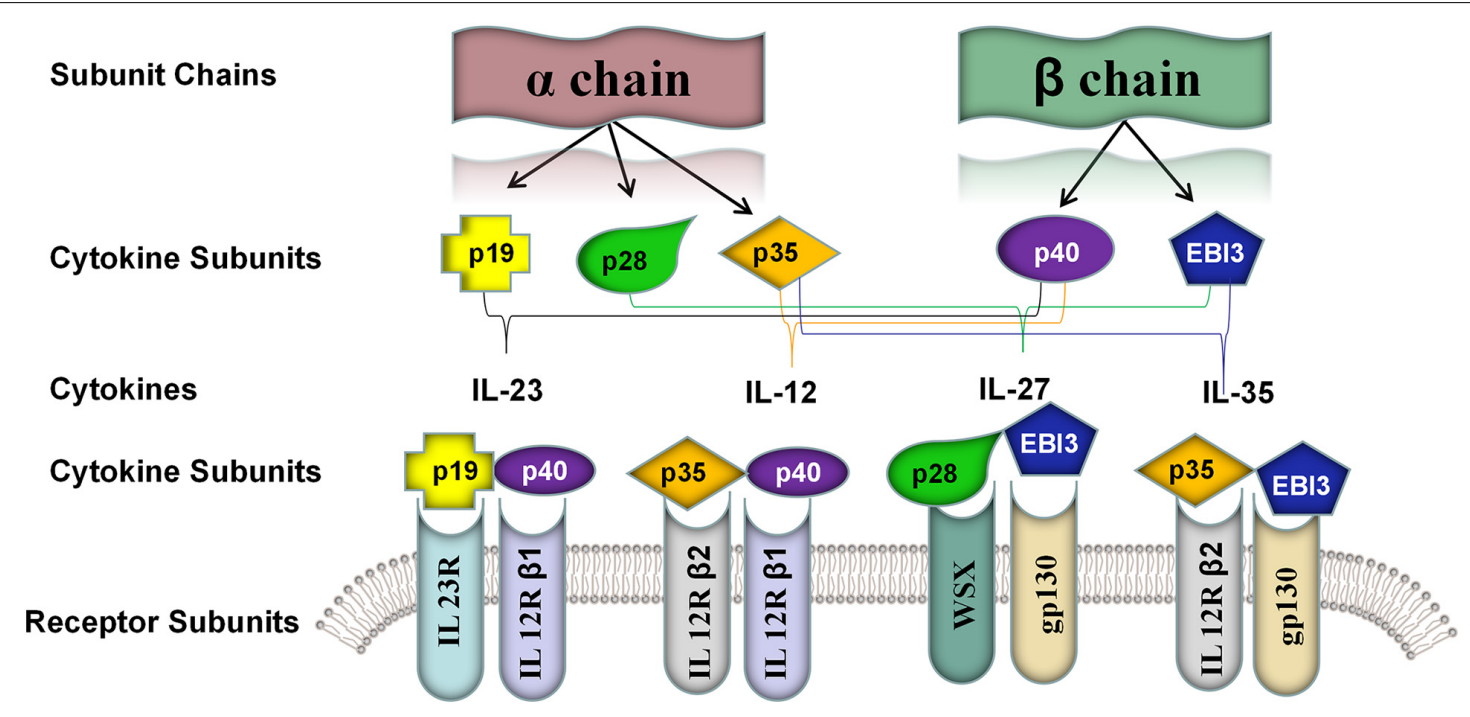

FIGURE 1 | Five known members of the IL-12 family cytokine subunits and their corresponding receptor subunits. The IL-12 family was characterized by different assembling of a $\alpha$ chain consisted of p19, p28, and p35 and $\beta$ chain consisted of $\mathrm{p} 40$ and EBI3. The members of IL-12 shared the subunits and their cognate receptors including IL-23R, IL-12R- $\beta 1$, IL-12R- $\beta 2$, IL-27R [WSX] and gp130. IL-23: p19 and p40; IL-12: p35 and p40; IL-27: p28 and EBI3; IL-35: p35 and EBI3; IL-39: p19 and EBI3.

and receptors (Figure 1; Bastian et al., 2019). Structurally, it was composed of the IL-27 $\beta$ chain EBI3 subunit and the IL- $12 \alpha$ chain p35 subunit. Although IL-12 family members share similar subunit structures, they have significantly different biological properties. Unlike other members of the IL-12 family, IL-35 showed strong immunosuppressive features (Collison et al., 2007; Su et al., 2018).

Human IL-35, expressed in response to inflammatory stimuli, was reported to inhibit proliferation and function of Teffs and convert the conventional $\mathrm{CD}^{+}{ }^{+} \mathrm{T}$ cells (Tconv) to highly inhibitory IL-35 induced regulatory $\mathrm{T}$ cell (iTr35), which further induced immune tolerance in hosts, and promoted viral infection (Collison et al., 2009; Shen et al., 2014). In a previous study, Collison et al. (2007) demonstrated that
IL-35 was implicated in the conversion of naive $\mathrm{T}$ cells into iTr35 in human or mouse. Transcriptional analysis revealed that there were highly restricted genes characteristics of $\mathrm{iTr} 35\left(\mathrm{CD}^{+}{ }^{+} \mathrm{Foxp}^{-} \mathrm{EBI}^{+} \mathrm{p}^{-} 5^{+} \mathrm{IL}_{10}{ }^{-} \mathrm{TGF} \beta^{-}\right)$, which were distinct from the other two types of Tregs (iTr), TGF- $\beta$-iTr $\left(\mathrm{CD}^{+}{ }^{+} \mathrm{Foxp}^{+}{ }^{+} \mathrm{TGF}-\beta^{+}\right)$and $\mathrm{IL}-10-\mathrm{iTr}\left(\mathrm{CD} 4^{+} \mathrm{Foxp}^{+}{ }^{+} \mathrm{IL}-10^{+}\right.$or $\mathrm{CD} 4^{+}$Foxp $3^{\text {negative }} \mathrm{IL}-10^{+}$), which were regulated by differential transcriptional regulators, respectively (Brockmann et al., 2018). Gene expression analysis indicated that IL-35 was distributed in broad tissues, and was a responsive anti-inflammatory cytokine induced by pro-inflammatory cytokines in a variety of non-T cells such as tumor cells, Bregs, dendritic cells (DCs), endothelial cells, smooth muscle cells, and monocytes (Li et al., 2012; Choi et al., 2015; Dixon et al., 2015). 


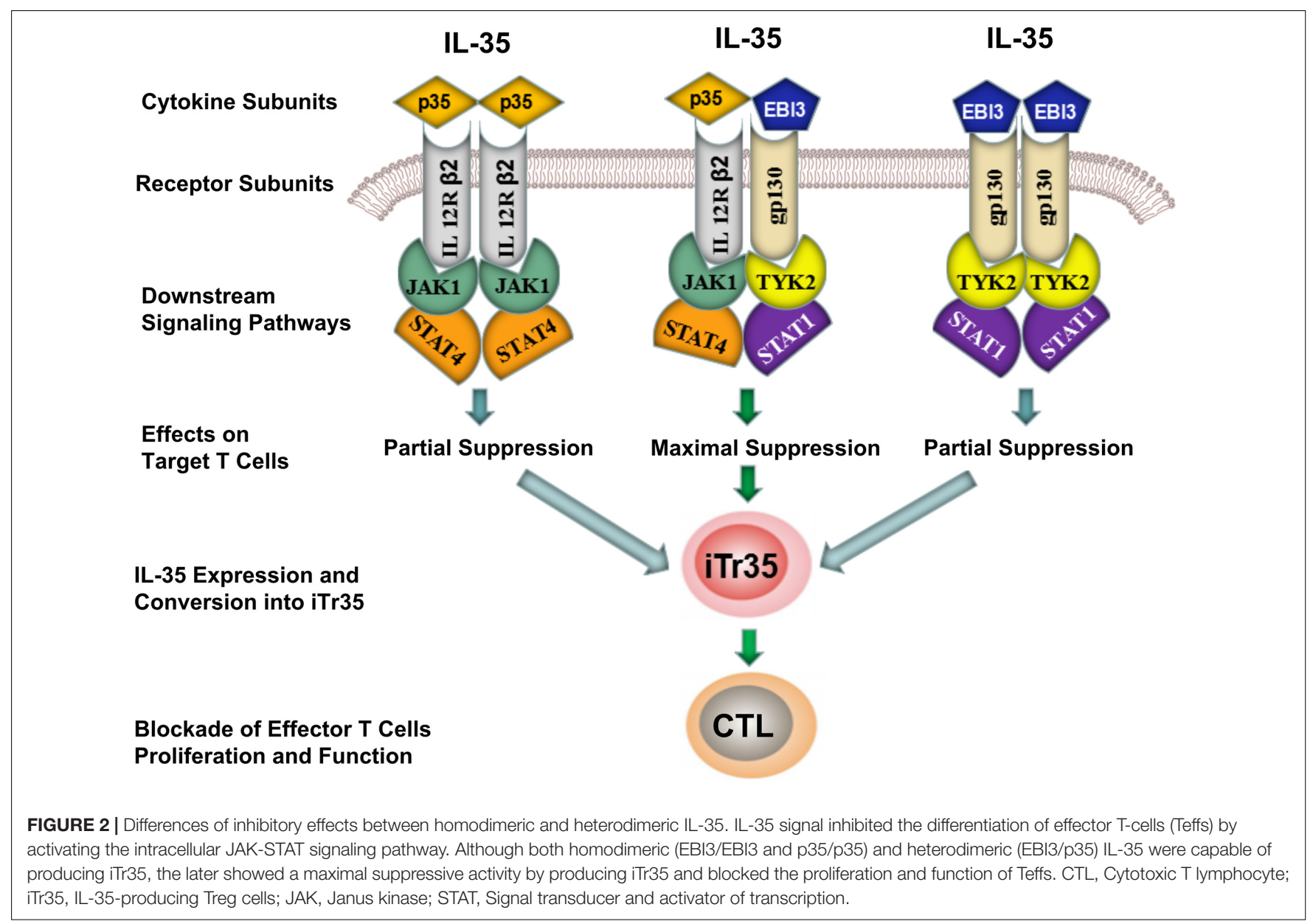

The transmission of IL-35 signals is mainly relied on a heterodimer formed by gp130 and IL-12R $\beta 2$ receptor chain subunits, or a homodimer of IL-12R $\beta 2$ or gp130 subunits. IL35 did not fully induce iTr35 transformation despite the fact that homodimeric IL-35 (i.e., EBI3/EBI3 and p35/p35) could block Teffs differentiation by activating one of its signaling pathways. In contrast, heterodimeric IL-35 (EBI3/p35) was capable of inducing iTr35 (Figure 2). Such difference was mainly associated with the downstream receptor signaling (Huang et al., 2017). The maximal suppressive activity of IL- 35 involves the formation of a unique heterodimers of IL12R $\beta 2$ and gp130, which subsequently binds the downstream transcriptional factors (i.e., STAT1 and STAT4). These combined transcriptional factors could uniquely bind with different sites in the p35 and EBI3 gene promoters. Thus, heterodimeric IL-35 contributed to the expression of p35 and EBI3, which formed a positive feedback loop modulating the secretion of IL-35 (Collison et al., 2012). As previously described, IL-35 rather than IL-12 or IFN- $\gamma$ promoted the conversion of Tconv cells into iTr35. Besides, it could induce STAT1 and STAT4 activation, which demonstrated that IL-35 was highly specific to STAT1 and STAT4 (Thierfelder et al., 1996; Hoey et al., 2003; Collison et al., 2012; Louis, 2016). In future, more studies focusing on the composition and function of these downstream receptors in the IL-35 signaling pathways are required to further illustrate the potential biological properties of IL-35.

Different from IL-12 family cytokines, the inhibitory activity of IL-35 was primarily on the CTL/Th cell proliferation and effector function. Among the subpopulations of Th cells, both Th1 and Th2 have been implicated in the pathogenesis of hepatic inflammation during HBV infection (Bertoletti and Ferrari, 2012). On one hand, IL-35 significantly inhibited immune activation of Th1/CTL cells together with secretion of IL-2 and IFN- $\gamma$ in inflammation and related diseases of animal disease models (Guo et al., 2017). On the other hand, IL-35 showed attenuating effects on allergen-specific $\mathrm{CD} 4^{+}$memory/effector Th2 cell-mediated airway inflammation (Huang et al., 2011). Th2 cells are in favor of anti-inflammation partly depending on the production of IL-10, as well as the secretion of other cytokines (e.g., IL-4, IL-5, and IL-13), which were induced by IL35 administration (Guo et al., 2017; Teymouri and Pirro, 2018). IL-10 is recognized as a key cytokine regulating the immune response to HBV infection. Das et al. (2012) reported that the down-regulation of IL-10 restores the function of exhausted HBV-specific $\mathrm{CD}^{+}{ }^{+} \mathrm{T}$ cells (Das et al., 2012; Liu et al., 2016). Moreover, IL-10 might substantially affect the antiviral immune response, as it inhibits the production of pro-inflammatory cytokines such as IFN- $\gamma$, tumor necrosis factor-alpha (TNF- $\alpha$ ), 
IL-1 $\beta$, and IL-6 (Rybicka et al., 2020). As recent studies suggest that rIL-35 fusion proteins can induce Breg cells to secret IL-10 (Wang et al., 2014), hence, is possible that IL-35 induce Th2 and Breg cells to secret IL-10, which was involved in immunologic tolerance in $\mathrm{CHB}$ patients.

Furthermore, IL-35 stimulation was shown to inhibit the differentiation of $\mathrm{HBV}$ core-specific $\left(\mathrm{CD} 4{ }^{+} \mathrm{CD} 25^{+} \mathrm{Foxp}^{+}\right)$ Tregs into a IL-17-secreting CD4 ${ }^{+} \mathrm{T}$ cells (Th17), and both of the Th subsets have been shown to be associated with disease progression or liver damage in CHB patients (Zhang et al., 2011; Cheng et al., 2015; Teng et al., 2019; Yang et al., 2019). Study indicated that the decreased Tregs/Th17 ratio and increased TGF- $\beta 1 /$ IL-17 ratio can be used independently to predict the prognosis and disease progression and may be associated with the survival and disease progression of patients (Yu et al., 2014). Besides, in vitro IL-35 stimulation reduced Th17 cell subset and Th17 cytokine production in $\mathrm{CD}^{+} \mathrm{T}$ cells from acute hepatitis B (AHB) patients (Teng et al., 2019). Moreover, in vivo treatment of IL-35 decreased the HBV-induced liver injury and reduced hepatic NK cells and HBV peptides-induced Th17 cells in HBV plasmid injected mouse model (Teng et al., 2019). Taken together, IL-35 was crucial for regulation of peripheral and hepatic HBV peptides-induced Th17 cells in vitro and in vivo, which might subsequently modulated hepatocytes damage and liver inflammation during acute HBV infection.

In $\mathrm{CHB}$ patients, the major biological roles of IL-35 are mainly associated with the disruption of the balance between the immunocytes, which triggered the increase of immunosuppressive cells in number and functional disorder. Meanwhile, IL-35 could trigger the decline of effector cells and the functional attenuation. It finally induced the pathogenesis and even the progression of inflammation-related diseases.

\section{IL-35 AND CHB}

For patient with HBV infection, virus elimination or persistency was closely related to the appropriate immune responses. Cytokines are known as important chemical mediators regulating the differentiation, proliferation and function of immune cells, which could trigger the pathogenesis of liver disease and affect various clinical presentations (Sodsai et al., 2013; Li et al., 2016; Nitschke et al., 2016). Accumulating evidence indicated that serum IL-35 showed significant increase in patients with chronic $\mathrm{HBV}$ infection. According to the previous description, serum IL-35 was positively correlated with HBV DNA load and Tregs levels, and there was a negative correlation between IL-35 and circulating effector CD8 ${ }^{+}$T cells (Li et al., 2015; Moreno-Cubero and Larrubia, 2016; Nitschke et al., 2016). These supported a potential role of IL-35 and iTr35 cells in maintaining the immune tolerance during $\mathrm{HBV}$ infection. However, the exact role of IL35 is still not completely understood, and further experiments and clinical trials are required to illustrate the role of IL-35 in this process.

As a responsive anti-inflammatory cytokine, IL-35 may have multifunctional roles involved in $\mathrm{HBV}$-induced liver diseases (Figure 3). Elevation of IL-35 was reported to contribute to immunosuppression in CHB by modulating the balance between Th17 and Tregs (Collison et al., 2010; Yang et al., 2019). Some studies showed that although the plasma IL-35 levels and circulating HBV peptide-induced Th17 frequency showed significant increase in patients with hepatitis B, IL-35 expression was negatively correlated with liver inflammation (Teng et al., 2019; Yang et al., 2019). Besides, in vivo IL-35 administration down-regulated HBV peptides-induced Th17 cells in the liver, suggesting IL-35 might be a novel mediator associated with hepatocytes damage and liver inflammation by regulating HBV peptides-induced Th17 cells during acute HBV infection (Teng et al., 2019). Our recent study also indicated that only a small amount of IL-35 could trigger significant inhibition on the proliferation of $\mathrm{CD} 4{ }^{+} \mathrm{CD} 25^{-} \mathrm{CD} 45 \mathrm{RA}^{+} \mathrm{T}$ cells. Similarly, it could significantly inhibit DCs proliferation and promote secretion of IL-10 and IL-6. Upon synergic stimuli by HBV core antigen peptide (Collison et al., 2007, 2010; Olson et al., 2012; Wang et al., 2014; Mitani et al., 2015; Shi et al., 2015; Shao et al., 2017; Vuddamalay and van Meerwijk, 2017; Flippe et al., 2019; Zhang et al., 2019) to the peripheral blood mononuclear cells (PBMCs) of CHB patients in vitro, IL-35 significantly inhibited the proliferation of HBV-specific CTL cells and IFN- $\gamma$ secretion (Li et al., 2015).

The regulation of IL-35 on virus-specific Tregs/Th17 balance may lead to viral persistence in chronic HBV infection. Zhou et al. (2015) showed that the IL-35 level was significant higher in $\mathrm{CD}^{+}{ }^{+} \mathrm{T}$ cells in patients with chronic HBV infection compared with that of the healthy individuals. Meanwhile, a high IL-35 level was related to a high $\mathrm{HBV}$ cccDNA replication in chronic $\mathrm{HBV}$ infection group, which indicated that HBV could induce the production of IL-35 by CD $4^{+} \mathrm{T}$ cells. Moreover, $\mathrm{HBV}$ infection also involved in the activation of immune system, while IL-35 showed immunosuppressive effects upon onset of chronic HBV infection. In a previous study, Tao et al. (2018) reported that IL-35 played a novel role in HBV replication. It had shown that IL35 participated in stimulating the transcription and replication of HBV through interacting with hepatocyte nuclear factor $4 \alpha$ (HNF4 $\alpha$ ). Recombinant human IL-35 (rhIL-35) promoted HBV DNA replication and secretion of $\mathrm{HBV}$ core antigen, hepatitis B surface antigen (HBsAg), and hepatitis B e antigen ( $\mathrm{HBeAg}$ ). This implied that HNF4 $\alpha$ may be a target for IL-35. On this basis, mutation of the HNF4 $\alpha$ binding site on the HBV core promoter or silencing $H N F 4 \alpha$ may abolish the IL-35-induced enhancement on HBV replication.

Among the diseases caused by viral infections, high IL35 was found to enhance the immunosuppressive activity of Tregs, and was positively correlated with the severity of diseases (e.g., CHB) (Damo and Joshi, 2019). According to previous description, Tregs and Th17 cells were closely interacted in the pathogenesis of viral infection. Specifically, Th17 cells contributed to the immune activation and disease progression, while Tregs may inhibit such process and play crucial roles in the maintenance of immune stability (Wan et al., 2020). In cases of chronic viral infection, there was high expression of Foxp3 and low expression of CD127 in the Tregs, which may directly promote the immune tolerance through direct cellular contact and inhibitory factors (e.g., IL-10 and IL-35) (Klein et al., 2010; 


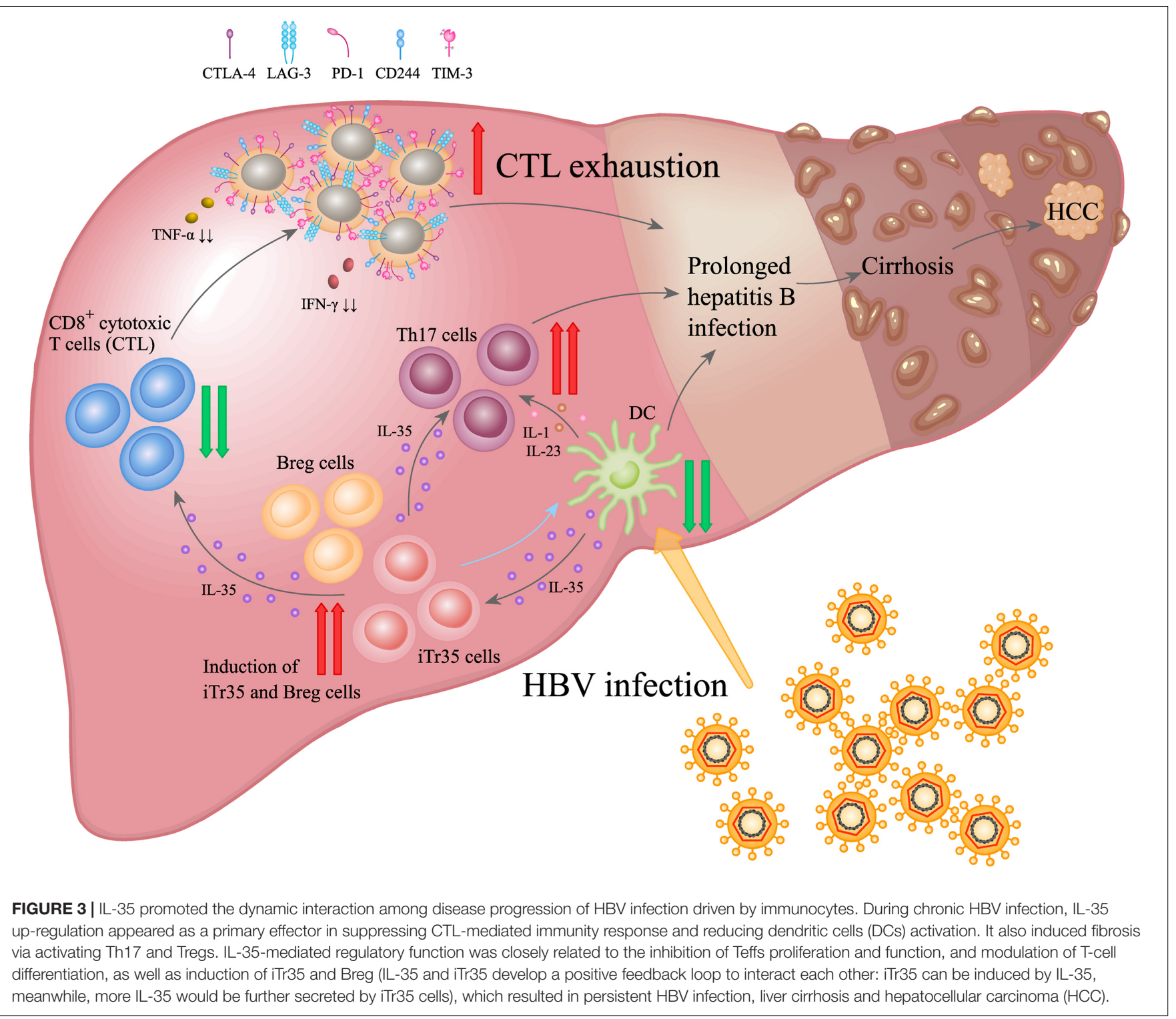

Karkhah et al., 2018). In Th17 cells, there was high expression of transcriptional factor retinoic acid-related orphan receptor $\gamma \mathrm{t}(\mathrm{ROR} \gamma \mathrm{t})$. Besides, it could secret the IL-17 and IL-22, which induced the hepatic inflammation and fibrosis associated with the HBV infection (Zhang et al., 2011; Zúñiga et al., 2013; Nikoopour et al., 2015; Paquissi, 2017). Tregs and Th17 imbalance was reported to be associated with the liver injury, and was also a risk factor for the hepatic fibrosis and HCC pathogenesis in CHB patients (Li et al., 2017; Liu et al., 2017). Furthermore, effective anti-viral therapy could down-regulate the response of $\mathrm{CD}^{+}{ }^{+} \mathrm{T}$ cells or $\mathrm{CD} 4{ }^{+} \mathrm{CD} 25^{+} \mathrm{CD} 127^{\mathrm{dim} /-}$ Tregs to IL-35 stimulation in vitro (Yang et al., 2019). Studies on Tregs in $\mathrm{HBV}$ infection indicated that the circulating $\mathrm{CD} 4{ }^{+} \mathrm{CD} 25^{+}$Tregs population was expanded in the persistence $\mathrm{HBV}$ infection patients (Manigold and Racanelli, 2007). It has been shown that Tregs could inhibit the HBV-specific CTL proliferation and the secretion of cytokines, which plays a role in suppressing antiviral $\mathrm{T}$ cell responses and aiding viral persistence (Knolle et al., 2015; Jung and Shin, 2016). Interestingly, in hepatitis B patients received anti-viral therapy, there was a decline of Tregs in the peripheral blood, accompanied with recovery of Teffs response. This contributed to the prediction of the efficiency treatment regimens (Sprengers et al., 2007; Stoop et al., 2007). In a recent study, Tregs derived IL-35 promoted the expression of $\mathrm{CD}^{+}$Tconv, $\mathrm{CD}^{+} \mathrm{T}$ cells and B lymphocytes inhibitory receptor, such as programmed cell death protein 1 (PD-1), $\mathrm{T}$ cell immunoglobulin and mucin domain 3 (TIM-3), cytotoxic T Lymphocyte-associated antigen-4 (CTLA-4) and lymphocyte activation gene 3 (LAG-3), which played important roles in the tolerance of infection (Sullivan et al., 2020).

The studies discussed above indicated that IL-35 played a double-edged sword role in the pathogenesis of $\mathrm{CHB}$. Specifically, it can induce the generation of Th17 cells, which thereby regulating the inflammation. Moreover, IL-35 played 
an important role in modulating the differentiation of Tregs with anti-inflammatory functions. IL-35 could trigger the upregulation of Tregs and regulate the specific Tregs/Th17 balance, which may contribute to viral persistence in chronic HBV infection. More importantly, $\mathrm{CD} 4{ }^{+} \mathrm{CD} 25^{+}$Tregs are able to inhibit activation and proliferation of effective $\mathrm{CD} 4^{+}$or $\mathrm{CD}^{+} \mathrm{T}$ cells, which then suppresses the amplification of HBV-specific CTLs and secretion of cytokines. Therefore, the immunosuppressive effects of IL-35 demonstrate that IL-35 can lead to imbalance of immune response and CTL exhaustion, leading to a poor immune response to $\mathrm{HBV}$. In general, the above results indicated a potential mechanism of IL-35-induced immunoregulation in chronic HBV infection.

\section{IL-35 AND HBV-RELATED LC}

Chronic HBV infection may induce deterioration of liver function through triggering liver injury and persistent liver inflammation, which subsequently resulted in paraplasm in the hepatic connective tissues and the consequential HBV-related liver fibrosis (HBV-LF), LC and even HCC (Xu et al., 2012). Various studies have suggested the pathology of HBV-related LC involves various immune components, especially immune cells and cytokines (e.g., IL-35) (Li et al., 2016; Tsai et al., 2018; Luo et al., 2019).

As mentioned above, IL-35 could directly inhibit the proliferation and function of Teffs, as well as the differentiation of Th17 cells. Meanwhile, it could expand the immunoregulatory reactions through the release of IL-35 from iTr35, which enhanced the tolerance to infection (Song and Ma, 2016). According to previous study, IL-35 pathway was closely associated with the progression of CHB to LC (liver cirrhosis), which implied that IL-35 may involve in the HBV-related LC (Shi et al., 2015). Additionally, the serum IL-35 in HBV-related LC patients was significantly higher compared with that of the normal control group, while serum IL-35 was positively correlated with IL-17, IL-22, and IL-33 which all acted as multifunctional roles involved in HBV infection (Wang et al., 2012; Zhao et al., 2014). Sun et al. (2012) indicated that the elevation of Th17 cells in hepatic cirrhosis patients would promote the activation of stellate cells in liver, which finally triggered the disease progression. At the early stage of $\mathrm{HBV}$ infection, Th17 could secret pro-inflammatory factors including IL-17, TGF- $\beta$ and IL-22. It seems that IL-35 in LC may play a role in sustaining the pathologic process, since increase of IL35 and other inflammatory cytokines (e.g., TGF- $\beta$, IL-22, IL-23, IL-31, and IL-33) can augment and extend hepatic inflammation (Cheng et al., 2015; Ming et al., 2015). For example, IL-35 can collaborate with TGF- $\beta$ to exert immunoregulatory function and then present effective and maximal anti-inflammatory outcome (Slawek et al., 2020). Previous studies found that the mRNA and protein expression of TGF- $\beta 1$ were significantly up-regulated in both the plasma and liver tissue in patients with fulminant liver failure (Miwa et al., 1997), and overexpression of TGF- $\beta 1$ delayed liver regeneration and promoted perisinusoidal fibrosis and hepatocyte apoptosis in the rat model of fulminant liver failure (Yoshimoto et al., 2005). Mechanically, IL-35 could prevent the binding of TGF- $\beta$ and its receptor, which inhibit phosphorylation of Smad3, a downstream effector of TGF$\beta$ receptor, thereby preventing the differentiation of Th17 cells and the synthesis of IL-17 in HBV-related LC patients (Ming et al., 2015).

All these indicated that IL-35 involved in the pathogenesis of the HBV related hepatic fibrosis. Therefore, attention should be paid to the side effects of IL-35 inhibition. Indeed, there is a long way for the application of such regimen for treating fibrotic diseases. On this basis, it is necessary to understand the relationship between IL-35 and fibrotic diseases for the development of new therapeutic approaches.

\section{IL-35 AND HBV-RELATED HCC}

Similar with the roles of IL-35 in CHB and LC, IL-35 appeared to exhibit immunosuppressive effects in HBV-related HCC. Several studies showed that high IL-35 was associated with poor prognosis in several malignancies, including HCC and gastric cancer (Friedman and Liao, 2015; Fu et al., 2016; Lumley et al., 2018; Teymouri and Pirro, 2018). Up to now, IL-35 played essential roles in restricting anti-cancer immunity and the $\mathrm{T}$ cell dysfunction in the tumor microenvironment. Turnis et al. (2016) revealed that Tregs derived IL-35 promoted the expression of several inhibitory receptors such as PD-1, LAG-3, and TIM-3, which then promoted the $\mathrm{T}$ cell exhaustion in tumor. In contrast, neutralization with an IL-35-specific antibody or Tregs-restricted deletion of IL-35 production limited tumor growth in multiple murine models of human cancer. Restriction of IL-35 level in tumor tissues contributed to the proliferation of Teffs, as well as their effecting function and the antigenic specificity. Therefore, Tregs and the associated cytokines formed the major barrier for the immunity against tumor.

In HCC tumor tissues, high IL-35 expression was associated with tumor cell invasion and poor prognosis. It was also an independent prognostic factor for HCC recurrence (Long et al., 2016; Damo and Joshi, 2019). To date, little is known about the roles of IL-35 in the pathogenesis of HCC. Secretion of IL-35 by liver tumor cells has been reported to associate with IL-35 up-regulation via a positive feedback, inhibition of proliferation, activation, cytotoxicity of $\mathrm{CD}^{+}{ }^{+} \mathrm{T}$ cells that promoted disease progression, and viral gene mutation and induction of tumor immune escape (Qiu et al., 2016; Damo and Joshi, 2019; Xue et al., 2019). IL-35 regulated the tumor microenvironment together with negative regulators (e.g., IL-18BP and IL-10), which played a key role in tumor immune escape, and promoted tumor progression and metastasis. It is an important factor in promoting tumorigenesis and development, and reduction of IL-35 may facilitate the control of disease progression (Xiang and Xie, 2015; Long et al., 2016). Meanwhile, it could limit the infiltration, effector function, and immune memory of antigen-specific $\mathrm{T}$ cells and promote the expression of various immunosuppressive receptors (e.g., PD-1, TIM3, CTLA-4, and LAG3), which thereby promoted T cell exhaustion in the tumor, and assisted tumor immune escape, tumor proliferation and 
metastasis (Vignali and Kuchroo, 2012; Fu et al., 2016; Sawant and Yano, 2019).

In tumor tissues, IL-35 involved in JAK/STAT pathway phosphorylation by recruiting bone marrow-derived $\mathrm{CD}_{11} \mathrm{~b}^{+} \mathrm{Gr}^{+}$inhibitory effector cells, which then promoted the tumor angiogenesis and immunosuppression of the tumor microenvironment (Facciabene et al., 2012; Liang et al., 2016; Long et al., 2016; Turnis et al., 2016). Therefore, the immunosuppressive activity and anti-inflammatory properties of IL-35 may be attributed to its potential in inhibiting Teffs amplification, as well as promoting the generation of IL-35 secreted iTr35 and Bregs in the tumor environment. Besides, it promoted host immune tolerance to infection and tumor cells, which played crucial roles in the pathogenesis of various diseases. This indicates that IL-35 may be a new target for the treatment of infectious diseases, malignancies, and inflammatory diseases.

\section{POSSIBLE IMMUNOREGULATORY MECHANISM OF IL-35 IN CHB}

As mentioned above, although there are various studies on the role of IL-35 in liver diseases, including $\mathrm{CHB}, \mathrm{LC}$, and HCC (Table 2), little is known about how IL-35 affects the HBV replication. To illustrate related mechanism, further researches are needed to investigate the immunopathology of IL-35. Currently, the immunoregulatory function of IL-35 can be depicted based on known upstream and downstream pathways (Figure 4). Downstream of IL-35, EBI3, and p35 subunits had been shown to form a tetramer by binding to the corresponding receptors (i.e., gp130 and IL-12R 32 ). In turn, intracellular JAK kinase was phosphorylated, which ultimately induced the phosphorylation of the downstream STAT transcriptional factor and certain gene expression upon translocation to a specific promoter site gene expression. The specific signaling pathway may be associated with the function of IL-35 (Olson et al., 2013; Egwuagu et al., 2015; Trehanpati and Vyas, 2017). In previously published study, the inhibition of Teffs proliferation and function mediated by IL-35 in vitro was in a dose-dependent manner, while activation of the STAT pathway was reported to participate in this process (Collison et al., 2010). However, our recent study suggested that IL-35 could activate the JAK1/TYK2STAT1/STAT4 pathway in CTLs in vitro, while IFN- $\gamma$ and TNF- $\alpha$ expression showed increase in CTLs when blocking the JAKSTAT pathway. In addition, the expression of the inhibitory receptors (e.g., PD-1, CTLA-4 and LAG-3) on CTLs was downregulated in the presence of JAK-STAT pathway blockage (Dong et al., 2020). IL-35 triggered the inhibition of HBV-specific CTLs function by modulating the JAK1/TYK2-STAT1/STAT4 pathway. Meanwhile, JAK-STAT pathway block could recover the function of CTL. In this regard, blockage of IL-10, IL-35, and IL-35 signaling pathways (e.g., JAK1 or STAT1) would lead to restore of Teffs function. This indeed contributed to HBV clearance, which may provide a new experimental basis for immunotherapy for CHB.

More studies are needed to elucidate the possible mechanisms involved in HBV-triggering production of IL-35. Study from Liu et al. (2011) provided first evidence that HBV may act as an inducer for the $\mathrm{CD} 4^{+} \mathrm{T}$ cells to initiate IL-35 secretion based on the data that both the mRNA expression of EBI3/p35 and the protein secretion of IL-35 were detectable in circulating $\mathrm{CD}^{+}{ }^{+} \mathrm{T}$ cells in patients with chronic hepatitis B. However, there remains a lack of research on IL-35 derived from Breg cells in $\mathrm{HBV}$ infection. Future investigations are needed to fully elucidate the molecular mechanism of how HBV trigger IL-35 secretion in persistent $\mathrm{HBV}$ infection and its related liver deterioration. With further advances in the understanding of IL-35 and its immunosuppressive mechanisms, it will be possible to design targeted immunotherapies and antivirus approaches to modulate the immune response for controlling persistent chronic HBV infection or deterioration in liver diseases.

$\mathrm{HBV}$ related proteins (e.g., $\mathrm{HBx}, \mathrm{HBs}, \mathrm{HBc}, \mathrm{HBe}$, preS1, and preS2) may be upstream protein associated with the IL35 secretion. The $H B x$ gene encoding the $\mathrm{HBx}$ protein was recognized as one of the most essential determinants for viral replication, dissemination, and viral-medicated pathogenesis (Slagle and Bouchard, 2018). The $\mathrm{HBx}$ protein served as a multifunctional $\mathrm{HBV}$ regulator that interacted with multiple

TABLE 2 | Immunoregulatory activities of IL-35 in HBV-related liver diseases.

\begin{tabular}{|c|c|c|c|c|}
\hline Disease & Action & Role & Outcomes reported & References \\
\hline $\mathrm{CHB}$ & $\begin{array}{l}\text { Significantly increased; Positively } \\
\text { correlated with HBV DNA load and } \\
\text { Tregs levels }\end{array}$ & $\begin{array}{l}\text { Modulate Tregs/Th17 balance; } \\
\text { Induction of effector T-cells exhaustion } \\
\text { and immunosuppression; Stimulating } \\
\text { HBV transcription and replication }\end{array}$ & $\begin{array}{l}\text { Lead to imbalance of immune } \\
\text { response and contribute to viral } \\
\text { persistence }\end{array}$ & $\begin{array}{l}\text { Li et al., 2015; Zhou et al., } \\
\text { 2015; Teng et al., 2019; } \\
\text { Yang et al., } 2019\end{array}$ \\
\hline HBV-related LC & $\begin{array}{l}\text { Significantly increased; Negatively } \\
\text { correlated with the albumin level and } \\
\text { the Child-Pugh score }\end{array}$ & $\begin{array}{l}\text { Augment and extend hepatic } \\
\text { inflammation; Sustaining the pathologic } \\
\text { process }\end{array}$ & $\begin{array}{l}\text { Enhance the tolerance to } \\
\text { infection, trigger the disease } \\
\text { progression }\end{array}$ & $\begin{array}{l}\text { Cheng et al., 2015; Shi } \\
\text { et al., 2015; Sun et al., } \\
\text { 2012; Slawek et al., } 2020\end{array}$ \\
\hline HBV-related HCC & $\begin{array}{l}\text { Notably elevated; Positively correlated } \\
\text { with Treg infiltration and HCC } \\
\text { aggressiveness; Negatively correlated } \\
\text { with TNM stage, histological grade, } \\
\text { tumor size, vascular invasion and lymph } \\
\text { node metastasis }\end{array}$ & $\begin{array}{l}\text { Reducing perforin expression and IFN- } \gamma \\
\text { production, elevating PD- } 1 \text { and CTLA- } 4 \\
\text { expression; Trigger the decline of } \\
\text { effector T-cells and the functional } \\
\text { attenuation }\end{array}$ & $\begin{array}{l}\text { Limit effective anti-tumor } \\
\text { immunity }\end{array}$ & $\begin{array}{l}\text { Fu et al., 2016; Long et al., } \\
\text { 2016; Qiu et al., 2016; } \\
\text { Damo and Joshi, } 2019\end{array}$ \\
\hline
\end{tabular}

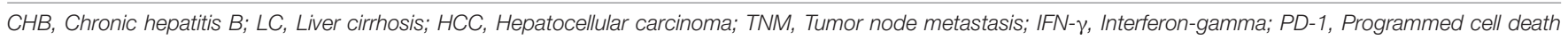
protein 1; CTLA-4, Cytotoxic T Lymphocyte-associated antigen-4. 


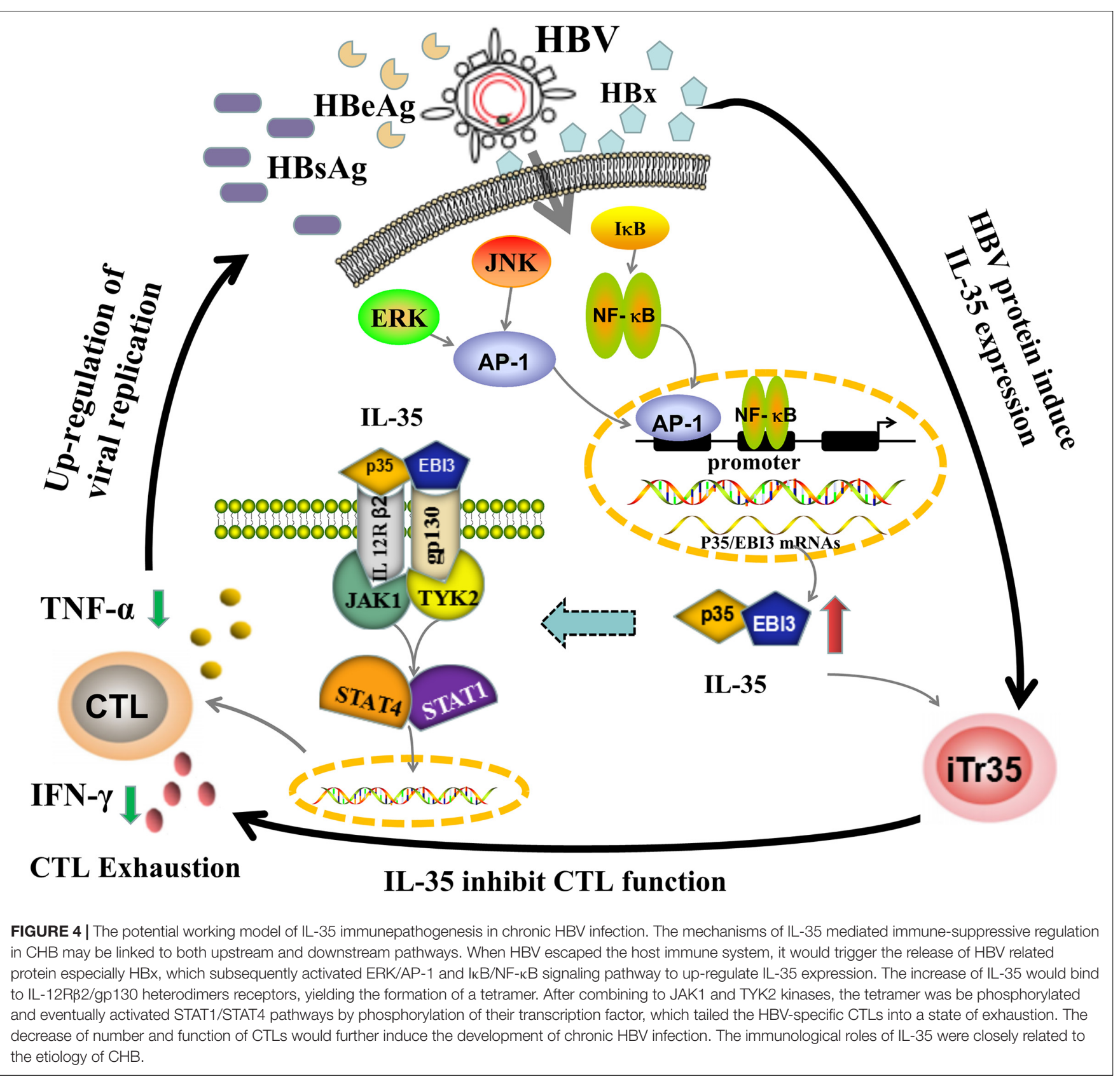

protein kinases in the cytosol. Secondly, it could act as a kinase activator or co-stimulatory molecule, which then directly activated target cellular promoters and enhancers to increase viral gene expression and replication. Taken together, HBx protein participated in intracellular signal transduction, colonization and transformation, and inhibited the hepatocellular apoptosis, and invasion and metastasis of HCC (Bagga et al., 2016). In the pathogenesis of CHB, HBx could activate ERK and NF$\kappa \mathrm{B}$ signaling pathways, and then triggered the up-regulation of IL-23 and over-expression of the transcription factor AP-1 of ERK/JNK signaling pathway that contributed to the proliferation of hepatoma cells (Shan et al., 2010; Xia et al., 2012). Also, it was implicated with the metabolism of arachidonic acid and activation of the ERK signaling pathway and its positive feedback loop, which subsequently promoted the pathogenesis of hepatic inflammation (Cho et al., 2015). Recently, it has been proposed that there are binding sites for AP-1 and NF- $\mathrm{KB}$ transcription factors in the p35/EBI3 subunit gene promoters. In particular, NF- $\kappa \mathrm{B}$ can directly activate the EBI3 gene promoter in bone marrow-derived DCs (Li et al., 2012; Song and Ma, 2016). Therefore, up-regulation of IL-35 expression in CHB patients may be mediated by the HBx/ERK/NF- $\mathrm{BB}$ pathway, which inhibited the function of Teffs and attenuated the antiviral immunity in hosts. Considering the roles of IL35 on the receptors and/or signaling pathways during HBV infection, it is reasonable to speculate that IL-35 may serve 
as a novel immunotherapy target for chronic $\mathrm{HBV}$ infection related diseases.

\section{CHALLENGES AND PROSPECTS}

HBV infection has caused great health problems and heavy economic burdens. Oral administration of nucleos(t)ide analogs is the main treatment option for anti-HBV therapy with most cases achieving a high virological suppression. For example, in patients treated with entecavir and tenofovir, more than $95 \%$ of patients' serum HBV DNA were below the detection limit. In addition, the long-term suppression of the virus by nucleo(t)ide analog therapy also resulted in significant improvement in liver histology and reduced the incidence of liver cirrhosis, as well as hepatocellular carcinoma (Wong et al., 2013; Wu et al., 2014; Seto et al., 2018). Its main disadvantages include the necessity of lifelong treatment, difficulty in the clearance of HBsAg in serum and the possibility of $\mathrm{HBV}$ reactivation. Therefore, there is an urgent need to explore new anti-inflammatory points and drug targets in order to establish effective treatment options. For the immunoregulatory therapy in treating HBV infection, it is necessary to develop regimens based on blocking checkpoint inhibitor, specific $\mathrm{T}$ cell vaccines and genetically engineered $\mathrm{T}$ cells such as chimeric antigen receptor (CAR) and TCR redirected $\mathrm{T}$ cells. These contribute to the restoration of aberrant HBV specific responses, which promoted the clearance of serum HBsAg (Ye et al., 2015; Boni et al., 2019a; Bertoletti and Tan, 2020). Previous studies suggested that intervention strategies may be helpful to the recovery of depleted $\mathrm{T}$ cells by blocking co-inhibitory pathways (Boni et al., 2019a; Meng et al., 2020). However, most of them are in the preclinical or phase I or II stage. These therapies include HBV-specific immunomodulators, such as immunostimulants [e.g., Inarigivir (SB 9200) and the anti-PD-1 antibody nivolumab] and therapeutic vaccines (e.g., GS-4774 and TG-1050) (Martin et al., 2017; Verdon et al., 2017; Yuen et al., 2018; Boni et al., 2019b). A novel CAR construct

\section{REFERENCES}

Asabe, S., Wieland, S. F., Chattopadhyay, P. K., Roederer, M., Engle, R. E., Purcell, R. H., et al. (2009). The size of the viral inoculum contributes to the outcome of hepatitis B virus infection. J. Virol. 83, 9652-9662. doi: 10.1128/JVI.00867-09

Bagga, S., Rawat, S., Ajenjo, M., and Bouchard, M. J. (2016). Hepatitis B virus (HBV) X protein-mediated regulation of hepatocyte metabolic pathways affects viral replication. Virology 498, 9-22. doi: 10.1016/j.virol.2016.08.006

Bastian, D., Wu, Y., Betts, B. C., and Yu, X. Z. (2019). The IL-12 cytokine and receptor family in graft-vs.-host disease. Front. Immunol. 10:988. doi: 10.3389/ fimmu.2019.00988

Bertoletti, A., and Ferrari, C. (2012). Innate and adaptive immune responses in chronic hepatitis B virus infections: towards restoration of immune control of viral infection. Gut 61, 1754-1764. doi: 10.1136/gutjnl-2011-301073

Bertoletti, A., and Gehring, A. J. (2006). The immune response during hepatitis B virus infection. J. Gen. Virol. 87(Pt 6), 1439-1449. doi: 10.1099/vir.0.81920-0

Bertoletti, A., and Tan, A. T. (2020). HBV as a target for CAR or TCR-T cell therapy. Curr. Opin. Immunol. 66, 35-41. doi: 10.1016/j.coi.2020.04.003

Boni, C., Barili, V., Acerbi, G., Rossi, M., Vecchi, A., Laccabue, D., et al. (2019a). HBV immune-therapy: from molecular mechanisms to clinical applications. Int. J. Mol. Sci. 20:2754. doi: 10.3390/ijms20112754 is developed to exert a profound influence on the expansion, differentiation, development, and survival of lymphocytes (Boni et al., 2019a; Bertoletti and Tan, 2020). Kruse et al. (2018) also reported that $\mathrm{HBsAg-CAR} \mathrm{T}$ cells have anti-HBV activity in an authentic preclinical HBV infection animal model. In addition, this new immunoregulatory therapy in treating HBV infection can reduce the HBsAg concentration to varying degrees, and induce HBsAg serum clearance in a few cases. Above experimental evidences suggest that immune-based therapies constitute a promising immune modulatory approach for a therapeutic restoration of protective immunity and serve as a new direction of current research in the field of liver diseases. Therefore, due to the IL-35 play a unique role in the IL12 family and show immunosuppressive activities on Teffs during $\mathrm{HBV}$ infection. Assessing the tissue and cellular origins of IL-35 during chronic HBV infection will help determine its potential as a biomarker for the diagnosis and prognostic evaluation of HBV. Elucidation of the immunopathologic roles of IL-35 in the progression of CHB may contribute to promise candidates for the development of new immunotherapeutic strategies targeting IL-35.

\section{AUTHOR CONTRIBUTIONS}

XLi drafted and revised the manuscript. XLiu participated in data collection and modified the figures. WW was critically revised and given the final approval of the version to be published. All authors have read and approved the article.

\section{FUNDING}

This work was supported, in part, by the grants from the National Natural Science Foundation of China (Nos. 82072357 and 81672092), and the Major National S\&T Projects for Infectious Diseases (2017ZX10202201-002-004).

Boni, C., Janssen, H. L. A., Rossi, M., Yoon, S. K., Vecchi, A., Barili, V., et al. (2019b). Combined GS-4774 and tenofovir therapy can improve HBV-specific t-cell responses in patients with chronic hepatitis. Gastroenterology 157, 227241 e7. doi: 10.1053/j.gastro.2019.03.044

Brockmann, L., Soukou, S., Steglich, B., Czarnewski, P., Zhao, L., Wende, S., et al. (2018). Molecular and functional heterogeneity of IL-10-producing CD4(+) T cells. Nat. Commun. 9:5457. doi: 10.1038/s41467-018-07 581-4

Cheng, L. S., Liu, Y., and Jiang, W. (2015). Restoring homeostasis of CD4+ $\mathrm{T}$ cells in hepatitis-B-virus-related liver fibrosis. World J. Gastroenterol. 21, 10721-10731. doi: 10.3748/wjg.v21.i38.10721

Cho, H. K., Kim, S. Y., Kyaw, Y. Y., Win, A. A., Koo, S. H., Kim, H. H., et al. (2015). HBx induces the proliferation of hepatocellular carcinoma cells via AP1 over-expressed as a result of ER stress. Biochem. J. 466, 115-121. doi: 10.1042/bj20140819

Choi, J., Leung, P. S., Bowlus, C., and Gershwin, M. E. (2015). IL-35 and autoimmunity: a comprehensive perspective. Clin. Rev. Allergy Immunol. 49, 327-332. doi: 10.1007/s12016-015-8468-9

Collison, L. W., Chaturvedi, V., Henderson, A. L., Giacomin, P. R., Guy, C., Bankoti, J., et al. (2010). IL-35-mediated induction of a potent regulatory T cell population. Nat. Immunol. 11, 1093-1101. doi: 10.1038/ni.1952 
Collison, L. W., Delgoffe, G. M., Guy, C. S., Vignali, K. M., Chaturvedi, V., Fairweather, D., et al. (2012). The composition and signaling of the IL-35 receptor are unconventional. Nat. Immunol. 13, 290-299. doi: 10.1038/ni.2227

Collison, L. W., Pillai, M. R., Chaturvedi, V., and Vignali, D. A. (2009). Regulatory $\mathrm{T}$ cell suppression is potentiated by target $\mathrm{T}$ cells in a cell contact, IL-35- and IL-10-dependent manner. J. Immunol. 182, 6121-6128. doi: 10.4049/jimmunol. 0803646

Collison, L. W., Workman, C. J., Kuo, T. T., Boyd, K., Wang, Y., Vignali, K. M., et al. (2007). The inhibitory cytokine IL-35 contributes to regulatory T-cell function. Nature 450, 566-569. doi: 10.1038/nature06306

Damo, M., and Joshi, N. S. (2019). T(reg) cell IL-10 and IL-35 exhaust CD8(+) T cells in tumors. Nat. Immunol. 20, 674-675. doi: 10.1038/s41590-019-0389-y

Dandri, M., and Locarnini, S. (2012). New insight in the pathobiology of hepatitis B virus infection. Gut 61(Suppl. 1), i6-i17. doi: 10.1136/gutjnl-2012-302056

Das, A., Ellis, G., Pallant, C., Lopes, A. R., Khanna, P., Peppa, D., et al. (2012). IL10 -producing regulatory $\mathrm{B}$ cells in the pathogenesis of chronic hepatitis $\mathrm{B}$ virus infection. J. Immunol. 189, 3925-3935. doi: 10.4049/jimmunol.1103139

Dixon, K. O., van der Kooij, S. W., Vignali, D. A., and van Kooten, C. (2015). Human tolerogenic dendritic cells produce IL-35 in the absence of other IL-12 family members. Eur. J. Immunol. 45, 1736-1747. doi: 10.1002/eji.201445217

Dong, Y., Li, X., Yu, Y., Lv, F., and Chen, Y. (2020). JAK/STAT signaling is involved in IL-35-induced inhibition of hepatitis B virus antigen-specific cytotoxic T cell exhaustion in chronic hepatitis B. Life Sci. 252, 117663. doi: 10.1016/j.lfs.2020. 117663

Egwuagu, C. E., Yu, C. R., Sun, L., and Wang, R. (2015). Interleukin 35: critical regulator of immunity and lymphocyte-mediated diseases. Cytokine Growth Factor Rev. 26, 587-593. doi: 10.1016/j.cytogfr.2015.07.013

Facciabene, A., Motz, G. T., and Coukos, G. (2012). T-regulatory cells: key players in tumor immune escape and angiogenesis. Cancer Res. 72, 2162-2171. doi: 10.1158/0008-5472.can-11-3687

Flippe, L., Bezie, S., Anegon, I., and Guillonneau, C. (2019). Future prospects for CD8(+) regulatory T cells in immune tolerance. Immunol. Rev. 292, 209-224. doi: 10.1111/imr.12812

Friedman, A., and Liao, K. L. (2015). The role of the cytokines IL-27 and IL-35 in cancer. Math. Biosci. Eng. 12, 1203-1217. doi: 10.3934/mbe.2015.12.1203

Fu, Y.-P., Yi, Y., Cai, X.-Y., Sun, J., Ni, X.-C., He, H.-W., et al. (2016). Overexpression of interleukin-35 associates with hepatocellular carcinoma aggressiveness and recurrence after curative resection. Br. J. Cancer 114, 767776. doi: 10.1038/bjc. 2016.47

Guo, H., Zhao, N., Gao, H., and He, X. (2017). Mesenchymal stem cells overexpressing interleukin-35 propagate immunosuppressive effects in mice. Scand. J. Immunol. 86, 389-395. doi: 10.1111/sji.12613

Hoey, T., Zhang, S., Schmidt, N., Yu, Q., Ramchandani, S., Xu, X., et al. (2003). Distinct requirements for the naturally occurring splice forms Stat4alpha and Stat4beta in IL-12 responses. EMBO J. 22, 4237-4248. doi: 10.1093/emboj/ $\operatorname{cdg} 393$

Huang, A., Cheng, L., He, M., Nie, J., Wang, J., and Jiang, K. (2017). Interleukin35 on $\mathrm{B}$ cell and $\mathrm{T}$ cell induction and regulation. J. Inflamm. (Lond.) 14:16. doi: 10.1186/s12950-017-0164-5

Huang, C. H., Loo, E. X. I, Kuo, C., Soh, G. H., Goh, D. L., Lee, B. W., et al. (2011). Airway inflammation and IgE production induced by dust mite allergenspecific memory/effector Th2 cell line can be effectively attenuated by IL- 35 . J. Immunol. 187, 462-471. doi: 10.4049/jimmunol.1100259

Jung, M. K., and Shin, E. C. (2016). Regulatory T cells in hepatitis B and C virus infections. Immune Netw. 16, 330-336. doi: 10.4110/in.2016.16.6.330

Karkhah, A., Javanian, M., and Ebrahimpour, S. (2018). The role of regulatory T cells in immunopathogenesis and immunotherapy of viral infections. Infect. Genet. Evol. 59, 32-37. doi: 10.1016/j.meegid.2018.01.015

Klein, S., Kretz, C. C., Krammer, P. H., and Kuhn, A. (2010). CD127(low/-) and FoxP3(+) expression levels characterize different regulatory T-cell populations in human peripheral blood. J. Invest. Dermatol. 130, 492-499. doi: 10.1038/jid. 2009.313

Knolle, P. A., Böttcher, J., and Huang, L. R. (2015). The role of hepatic immune regulation in systemic immunity to viral infection. Med. Microbiol. Immunol. 204, 21-27. doi: 10.1007/s00430-014-0371-0

Kruse, R. L., Shum, T., Tashiro, H., Barzi, M., Yi, Z., Whitten-Bauer, C., et al. (2018). HBsAg-redirected T cells exhibit antiviral activity in HBV-infected human liver chimeric mice. Cytotherapy 20, 697-705. doi: 10.1016/j.jcyt.2018.02.002
Lee, H. M., and Banini, B. A. (2019). Updates on chronic HBV: current challenges and future goals. Curr. Treat. Options Gastroenterol. 17, 271-291. doi: 10.1007/ s11938-019-00236-3

Li, K., Liu, H., and Guo, T. (2017). Th17/Treg imbalance is an indicator of liver cirrhosis process and a risk factor for HCC occurrence in HBV patients. Clin. Res. Hepatol. Gastroenterol. 41, 399-407. doi: 10.1016/j.clinre.2016.12.004

Li, X., Liu, X., Tian, L., and Chen, Y. (2016). Cytokine-mediated immunopathogenesis of hepatitis B virus infections. Clin. Rev. Allergy Immunol. 50, 41-54. doi: 10.1007/s12016-014-8465-4

Li, X., Mai, J., Virtue, A., Yin, Y., Gong, R., Sha, X., et al. (2012). IL-35 is a novel responsive anti-inflammatory cytokine-a new system of categorizing anti-inflammatory cytokines. PLoS One 7:e33628. doi: 10.1371/journal.pone. 0033628

Li, X., Tian, L., Dong, Y., Zhu, Q., Wang, Y., Han, W., et al. (2015). IL-35 inhibits HBV antigen-specific IFN- $\gamma$-producing CTLs in vitro. Clin. Sci. (Lond.) 129, 395-404. doi: 10.1042/cs20140511

Liang, Y., Chen, Q., Du, W., Chen, C., Li, F., Yang, J., et al. (2016). Epsteinbarr virus-induced gene 3 (EBI3) blocking leads to induce antitumor cytotoxic $\mathrm{t}$ lymphocyte response and suppress tumor growth in colorectal cancer by bidirectional reciprocal-regulation STAT3 signaling pathway. Mediators Inflamm. 2016:3214105. doi: 10.1155/2016/3214105

Liu, B., Gao, W., Zhang, L., Wang, J., Chen, M., Peng, M., et al. (2017). Th17/Treg imbalance and increased interleukin-21 are associated with liver injury in patients with chronic severe hepatitis B. Int. Immunopharmacol. 46, 48-55. doi: 10.1016/j.intimp.2017.02.019

Liu, F., Tong, F., He, Y., and Liu, H. (2011). Detectable expression of IL-35 in CD4+ $\mathrm{T}$ cells from peripheral blood of chronic hepatitis B patients. Clin. Immunol. 139, 1-5. doi: 10.1016/j.clim.2010.12.012

Liu, Y., Cheng, L. S., Wu, S. D., Wang, S. Q., Li, L., She, W. M., et al. (2016). IL-10-producing regulatory B-cells suppressed effector T-cells but enhanced regulatory T-cells in chronic HBV infection. Clin. Sci. (Lond.) 130, 907-919. doi: 10.1042/CS20160069

Long, J., Guo, H., Cui, S., Zhang, H., Liu, X., Li, D., et al. (2016). IL-35 expression in hepatocellular carcinoma cells is associated with tumor progression. Oncotarget 7, 45678-45686. doi: 10.18632/oncotarget.10141

Louis, P. R. B. I. V. S. (2016). "Post-transcriptional regulation of cytokine signaling during inflammatory responses," in Post-Transcriptional Mechanisms in Endocrine Regulation, eds K. Menon and A. Goldstrohm (Cham: Springer), 55-70. doi: 10.1007/978-3-319-25124-0_3

Lumley, S. F., McNaughton, A. L., Klenerman, P., Lythgoe, K. A., and Matthews, P. C. (2018). Hepatitis B virus adaptation to the CD8+ T cell response: consequences for host and pathogen. Front. Immunol. 9:1561. doi: 10.3389/ fimmu.2018.01561

Luo, M., Peng, H., Chen, P., and Zhou, Y. (2019). The immunomodulatory role of interleukin-35 in fibrotic diseases. Expert Rev. Clin. Immunol. 15, 431-439. doi: 10.1080/1744666x.2019.1564041

Manigold, T., and Racanelli, V. (2007). T-cell regulation by CD4 regulatory T cells during hepatitis B and $\mathrm{C}$ virus infections: facts and controversies. Lancet Infect. Dis. 7, 804-813. doi: 10.1016/s1473-3099(07)70289-x

Martin, C. F., Sprinzl, F., Leroy, V., Pol, S., Habersetzer, F., Thimme, R., et al. (2017). Phase 1 b clinical trial of TG1050 a novel HBV-targeted immunotherapy in NUC suppressed chronic hepatitis B (CHB) patients: safety and early immunological data following single administration. Hepatology 66(suppl. 1), 483A-484A.

Meng, Z., Chen, Y., and Lu, M. (2020). Advances in targeting the innate and adaptive immune systems to cure chronic hepatitis B virus infection. Front. Immunol. 10:3127. doi: 10.3389/fimmu.2019.03127

Ming, D., Yu, X., Guo, R., Deng, Y., Li, J., Lin, C., et al. (2015). Elevated TGF- $\beta 1 /$ IL31 pathway is associated with the disease severity of hepatitis B virus-related liver cirrhosis. Viral. Immunol. 28, 209-216. doi: 10.1089/vim.2014.0142

Mitani, A., Niedbala, W., Fujimura, T., Mogi, M., Miyamae, S., Higuchi, N., et al. (2015). Increased expression of interleukin (IL)-35 and IL-17, but not IL-27, in gingival tissues with chronic periodontitis. J. Periodontol. 86, 301-309. doi: 10.1902/jop.2014.140293

Miwa, Y., Harrison, P. M., Farzaneh, F., Langley, P. G., Williams, R., and Hughes, R. D. (1997). Plasma levels and hepatic mRNA expression of transforming growth factor-betal in patients with fulminant hepatic failure. J. Hepatol. 27, 780-788. doi: 10.1016/s0168-8278(97)80313-3 
Moreno-Cubero, E., and Larrubia, J. R. (2016). Specific CD8(+) T cell response immunotherapy for hepatocellular carcinoma and viral hepatitis. World J. Gastroenterol. 22, 6469-6483. doi: 10.3748/wjg.v22.i28.6469

Nikoopour, E., Bellemore, S. M., and Singh, B. (2015). IL-22, cell regeneration and autoimmunity. Cytokine 74, 35-42. doi: 10.1016/j.cyto.2014.09.007

Nitschke, K., Luxenburger, H., Kiraithe, M. M., Thimme, R., and NeumannHaefelin, C. (2016). CD8+ T-cell responses in hepatitis B and C: the (HLA-) A, B, and C of hepatitis B and C. Dig. Dis. 34, 396-409. doi: 10.1159/000444555

Olson, B. M., Jankowska-Gan, E., Becker, J. T., Vignali, D. A., Burlingham, W. J., and McNeel, D. G. (2012). Human prostate tumor antigen-specific CD8+ regulatory T cells are inhibited by CTLA-4 or IL-35 blockade. J. Immunol. 189, 5590-5601. doi: 10.4049/jimmunol.1201744

Olson, B. M., Sullivan, J. A., and Burlingham, W. J. (2013). Interleukin 35: a key mediator of suppression and the propagation of infectious tolerance. Front. Immunol. 4:315. doi: 10.3389/fimmu.2013.00315

Paquissi, F. C. (2017). Immunity and fibrogenesis: the role of Th17/IL-17 Axis in $\mathrm{HBV}$ and HCV-induced chronic hepatitis and progression to cirrhosis. Front. Immunol. 8:1195. doi: 10.3389/fimmu.2017.01195

Polaris Observatory Collaborators (2018). Global prevalence, treatment, and prevention of hepatitis B virus infection in 2016: a modelling study. Lancet Gastroenterol. Hepatol. 3, 383-403. doi: 10.1016/s2468-1253(18)30056-6

Qiu, X., Wang, X., Song, Y., and Chen, L. (2016). Plasma level of interleukin-35 as an independent prognostic indicator in hepatocellular carcinoma. Dig. Dis. Sci. 61, 3513-3521. doi: 10.1007/s10620-016-4270-7

Rybicka, M., Woziwodzka, A., Sznarkowska, A., Romanowski, T., Stalke, P., Dreczewski, M., et al. (2020). Genetic variation in IL-10 influences the progression of hepatitis B infection. Int. J. Infect. Dis. 96, 260-265. doi: 10.1016/ j.ijid.2020.04.079

Sawant, D. V., and Yano, H. (2019). Adaptive plasticity of IL-10(+) and IL-35(+) $\mathrm{T}(\mathrm{reg})$ cells cooperatively promotes tumor T cell exhaustion. Nat. Immunol. 20, 724-735. doi: 10.1038/s41590-019-0346-9

Seetharam, A., Perrillo, R., and Gish, R. (2014). Immunosuppression in patients with chronic hepatitis B. Curr. Hepatol. Rep. 13, 235-244. doi: 10.1007/s11901014-0238-2

Seto, W.-K., Lo, Y.-R., Pawlotsky, J.-M., and Yuen, M.-F. (2018). Chronic hepatitis B virus infection. Lancet 392, 2313-2324. doi: 10.1016/s0140-6736(18)31865-8

Shan, C., Xu, F., Zhang, S., You, J., You, X., Qiu, L., et al. (2010). Hepatitis B virus $\mathrm{X}$ protein promotes liver cell proliferation via a positive cascade loop involving arachidonic acid metabolism and p-ERK1/2. Cell Res. 20, 563-575. doi: $10.1038 /$ cr.2010.49

Shao, X., Ma, J., Jia, S., Yang, L., Wang, W., and Jin, Z. (2017). Interleukin-35 suppresses antiviral immune response in chronic hepatitis B virus infection. Front. Cell. Infect. Microbiol. 7:472. doi: 10.3389/fcimb.2017.00472

Shen, P., Roch, T., Lampropoulou, V., O'Connor, R. A., Stervbo, U., Hilgenberg, E., et al. (2014). IL-35-producing B cells are critical regulators of immunity during autoimmune and infectious diseases. Nature 507, 366-370. doi: 10.1038/ nature12979

Shi, M., Wei, J., Dong, J., Meng, W., Ma, J., Wang, T., et al. (2015). Function of interleukin-17 and -35 in the blood of patients with hepatitis B-related liver cirrhosis. Mol. Med. Rep. 11, 121-126. doi: 10.3892/mmr.2014.2681

Slagle, B. L., and Bouchard, M. J. (2018). Role of HBx in hepatitis B virus persistence and its therapeutic implications. Curr. Opin. Virol. 30, 32-38. doi: 10.1016/j. coviro.2018.01.007

Slawek, A., Lorek, D., Kedzierska, A. E., and Chelmonska-Soyta, A. (2020). Regulatory B cells with IL-35 and IL-10 expression in a normal and abortionprone murine pregnancy model. Am. J. Reprod. Immunol. 83:e13217. doi: 10. 1111/aji.13217

Sodsai, P., Surakiatchanukul, T., Kupatawintu, P., Tangkitvanich, P., and Hirankarn, N. (2013). Association of cytokine and cytokine receptor gene polymorphisms with the risk of chronic hepatitis B. Asian Pac.J. Allergy Immunol. 31, 277-285. doi: 10.12932/ap0284.31.4.2013

Song, M., and Ma, X. (2016). The immunobiology of interleukin-35 and its regulation and gene expression. Adv. Exp. Med. Biol. 941, 213-225. doi: 10.1007/ 978-94-024-0921-5_10

Sprengers, D., Stoop, J. N., Binda, R. S., Kusters, J. G., Haagmans, B. L., Carotenuto, P., et al. (2007). Induction of regulatory T-cells and interleukin-10-producing cells in non-responders to pegylated interferon-alpha therapy for chronic hepatitis B. Antivir. Ther. 12, 1087-1096.
Stoop, J. N., van der Molen, R. G., Kuipers, E. J., Kusters, J. G., and Janssen, H. L. (2007). Inhibition of viral replication reduces regulatory T cells and enhances the antiviral immune response in chronic hepatitis B. Virology 361, 141-148. doi: 10.1016/j.virol.2006.11.018

Su, L. C., Liu, X. Y., Huang, A. F., and Xu, W. D. (2018). Emerging role of IL-35 in inflammatory autoimmune diseases. Autoimmun. Rev. 17, 665-673. doi: 10.1016/j.autrev.2018.01.017

Sullivan, J. A., Tomita, Y., Jankowska-Gan, E., Lema, D. A., Arvedson, M. P., Nair, A., et al. (2020). Treg-cell-derived IL-35-coated extracellular vesicles promote infectious tolerance. Cell Rep. 30, 1039-1051.e5. doi: 10.1016/j.celrep.2019.12. 081

Sun, H. Q., Zhang, J. Y., Zhang, H., Zou, Z. S., Wang, F. S., and Jia, J. H. (2012). Increased Th17 cells contribute to disease progression in patients with HBVassociated liver cirrhosis. J. Viral. Hepat. 19, 396-403. doi: 10.1111/j.1365-2893. 2011.01561.x

Tang, L. S. Y., Covert, E., Wilson, E., and Kottilil, S. (2018). Chronic hepatitis B infection. JAMA 319:1802. doi: 10.1001/jama.2018.3795

Tao, N. N., Gong, R., Chen, X., He, L., Ren, F., Yu, H. B., et al. (2018). Interleukin35 stimulates hepatitis $\mathrm{B}$ virus transcription and replication by targeting transcription factor HNF4a. J. Gen. Virol. 99, 645-654. doi: 10.1099/jgv.0. 001050

Teng, D. K., Liu, Y., Lv, Y. F., Wang, L., Zhang, W., Wang, J. P., et al. (2019). Elevated interleukin- 35 suppresses liver inflammation by regulation of $\mathrm{T}$ helper 17 cells in acute hepatitis B virus infection. Int. Immunopharmacol. 70, 252-259. doi: 10.1016/j.intimp.2019.02.048

Terrault, N. A., Lok, A. S. F., McMahon, B. J., Chang, K. M., Hwang, J. P., Jonas, M. M., et al. (2018). Update on prevention, diagnosis, and treatment of chronic hepatitis B: AASLD 2018 hepatitis B guidance. Hepatology 67, 1560-1599. doi: 10.1002/hep. 29800

Teymouri, M., and Pirro, M. (2018). IL-35, a hallmark of immune-regulation in cancer progression, chronic infections and inflammatory diseases. Int. J. Cancer 143, 2105-2115. doi: 10.1002/ijc.31382

Thierfelder, W. E., van Deursen, J. M., Yamamoto, K., Tripp, R. A., Sarawar, S. R., Carson, R. T., et al. (1996). Requirement for Stat4 in interleukin-12mediated responses of natural killer and T cells. Nature 382, 171-174. doi: 10.1038/382171a0

Thimme, R., Wieland, S., Steiger, C., Ghrayeb, J., Reimann, K. A., Purcell, R. H., et al. (2003). CD8(+) T cells mediate viral clearance and disease pathogenesis during acute hepatitis B virus infection. J. Virol. 77, 68-76. doi: 10.1128/jvi.77. 1.68-76.2003

Tong, M. J., Hsu, L., Hsien, C., Kao, J. H., Durazo, F. A., Saab, S., et al. (2010). A comparison of hepatitis B viral markers of patients in different clinical stages of chronic infection. Hepatol. Int. 4, 516-522. doi: 10.1007/s12072-0109179-1

Trehanpati, N., and Vyas, A. K. (2017). Immune regulation by T regulatory cells in hepatitis B virus-related inflammation and cancer. Scand. J. Immunol. 85, 175-181. doi: 10.1111/sji.12524

Tsai, K. N., Kuo, C. F., and Ou, J. J. (2018). Mechanisms of hepatitis B virus persistence. Trends Microbiol. 26, 33-42. doi: 10.1016/j.tim.2017.07.006

Turnis, M. E., Sawant, D. V., Szymczak-Workman, A. L., Andrews, L. P., Delgoffe, G. M., Yano, H., et al. (2016). Interleukin-35 limits anti-tumor immunity. Immunity 44, 316-329. doi: 10.1016/j.immuni.2016.01.013

Verdon, D., Brooks, A. E., Gaggar, A., Woo, J., Schwabe, C., Subramanian, M., et al. (2017). Immunological assessment of HBeAg-negative chronic hepatitis B patient responses following anti-PD-1 treatment. Hepatology 66(suppl. 1):23A.

Vignali, D. A., and Kuchroo, V. K. (2012). IL-12 family cytokines: immunological playmakers. Nat. Immunol. 13, 722-728. doi: 10.1038/ni.2366

Vlachogiannakos, J., and Papatheodoridis, G. V. (2018). Hepatitis B: who and when to treat? Liver Int 38(Suppl. 1), 71-78. doi: 10.1111/liv.13631

Vuddamalay, Y., and van Meerwijk, J. P. (2017). CD28(-) and CD28(low)CD8(+) Regulatory T Cells: of Mice and Men. Front. Immunol. 8:31. doi: 10.3389/ fimmu.2017.00031

Wan, Z., Zhou, Z., Liu, Y., Lai, Y., Luo, Y., Peng, X., et al. (2020). Regulatory $\mathrm{T}$ cells and $\mathrm{T}$ helper 17 cells in viral infection. Scand. J. Immunol. 91:e12873. doi: $10.1111 /$ sji. 12873

Wang, J., Cai, Y., Ji, H., Feng, J., Ayana, D. A., Niu, J., et al. (2012). Serum IL33 levels are associated with liver damage in patients with chronic hepatitis $B$. J. Interferon Cytokine Res. 32, 248-253. doi: 10.1089/jir.2011.0109 
Wang, R. X., Yu, C. R. I, Dambuza, M., Mahdi, R. M., Dolinska, M. B., Sergeev, Y. V., et al. (2014). Interleukin-35 induces regulatory B cells that suppress autoimmune disease. Nat. Med. 20, 633-641. doi: 10.1038/nm. 3554

Wong, G. L.-H., Chan, H. L.-Y., Mak, C. W.-H., Lee, S. K.-Y., Ip, Z. M.-Y., Lam, A. T.-H., et al. (2013). Entecavir treatment reduces hepatic events and deaths in chronic hepatitis B patients With liver cirrhosis. Hepatology 58, 1537-1547. doi: 10.1002/hep.26301

World Health Organization (2013). Global Alert and Response (GAR). Hepatitis B. Available online at: http://www.who.int/csr/disease/hepatitis/ whocdscsrlyo20022/en/index1.html (accessed May 29, 2019).

World Health Organization (2017). Global Hepatitis Report. Geneva: World Health Organization.

Wu, C.-Y., Lin, J.-T., Ho, H. J., Su, C.-W., Lee, T.-Y., Wang, S.-Y., et al. (2014). Association of Nucleos(t)ide analogue therapy with reduced risk of hepatocellular carcinoma in patients with chronic hepatitis B-A Nationwide cohort study. Gastroenterology 147, 143-151.e5. doi: 10.1053/j.gastro.2014.03. 048

Xia, L., Tian, D., Huang, W., Zhu, H., Wang, J., Zhang, Y., et al. (2012). Upregulation of IL-23 expression in patients with chronic hepatitis B is mediated by the HBx/ERK/NF-кB pathway. J. Immunol. 188, 753-764. doi: 10.4049/jimmunol.1101652

Xiang, X. G., and Xie, Q. (2015). IL-35 a potential therapeutic target for controlling hepatitis B virus infection. J. Dig. Dis. 16, 1-6. doi: 10.1111/1751-2980. 12218

Xu, R., Zhang, Z., and Wang, F. S. (2012). Liver fibrosis: mechanisms of immunemediated liver injury. Cell. Mol. Immunol. 9, 296-301. doi: 10.1038/cmi.20 11.53

Xue, W., Yan, D., and Kan, Q. (2019). Interleukin-35 as an emerging player in tumor microenvironment. J. Cancer 10, 2074-2082. doi: 10.7150/jca.29170

Yang, L., Jia, S., Shao, X., Liu, S., Zhang, Q., Song, J., et al. (2019). Interleukin35 modulates the balance between viral specific CD4(+)CD25(+)CD127(dim/-) regulatory $\mathrm{T}$ cells and $\mathrm{T}$ helper 17 cells in chronic hepatitis $\mathrm{B}$ virus infection. Virol. J. 16:48. doi: 10.1186/s12985-019-1158-0

Yang, Z., Tang, T., Wei, X., Yang, S., and Tian, Z. (2015). Type 1 innate lymphoid cells contribute to the pathogenesis of chronic hepatitis B. Innate Immun. 21, 665-673. doi: 10.1177/1753425915586074

Ye, B., Liu, X., Li, X., Kong, H., Tian, L., and Chen, Y. (2015). T-cell exhaustion in chronic hepatitis B infection: current knowledge and clinical significance. Cell Death Dis. 6:e1694. doi: 10.1038/cddis.2015.42
Yoshimoto, N., Togo, S., Kubota, T., Kamimukai, N., Saito, S., Nagano, Y., et al. (2005). Role of transforming growth factor-betal (TGF-beta1) in endotoxininduced hepatic failure after extensive hepatectomy in rats. J. Endotoxin Res. 11, 33-39. doi: 10.1179/096805105225006650

Yu, X., Guo, R., Ming, D., Su, M., Lin, C., Deng, Y., et al. (2014). Ratios of regulatory $\mathrm{T}$ cells/T-helper 17 cells and transforming growth factor-beta1/interleukin-17 to be associated with the development of hepatitis B virus-associated liver cirrhosis. J. Gastroenterol. Hepatol. 29, 1065-1072. doi: 10.1111/jgh.12459

Yuen, M. F., Elkashab, M., Chen, C. Y., Coffin, C., Fung, S., Greenbloom, S., et al. (2018). Dose response and safety of the daily, oral RIG-I agonist Inarigivir (SB 9200) in treatment naïve patients with chronic hepatitis B: results from the $25 \mathrm{mg}$ and $50 \mathrm{mg}$ cohorts in the ACHIEVE trial. J. Hepatol. 68, S509-S510. doi: 10.1016/s0168-8278(18)31267-4

Zhang, J., Zhang, Y., Wang, Q., Li, C., Deng, H., Si, C., et al. (2019). Interleukin-35 in immune-related diseases: protection or destruction. Immunology 157, 13-20. doi: 10.1111/imm.13044

Zhang, Y., Cobleigh, M. A., Lian, J. Q., Huang, C. X., Booth, C. J., Bai, X. F., et al. (2011). A proinflammatory role for interleukin-22 in the immune response to hepatitis B virus. Gastroenterology 141, 1897-1906. doi: 10.1053/j.gastro.2011. 06.051

Zhao, J., Zhang, Z., Luan, Y., Zou, Z., Sun, Y., Li, Y., et al. (2014). Pathological functions of interleukin-22 in chronic liver inflammation and fibrosis with hepatitis $\mathrm{B}$ virus infection by promoting $\mathrm{T}$ helper 17 cell recruitment. Hepatology 59, 1331-1342. doi: 10.1002/hep.26916

Zhou, Y., Zhang, H., and Li, Y. (2015). IL-35 expression in peripheral blood CD4(+) $\mathrm{T}$ cells from chronic hepatitis B virus-infected patients directly correlates with virus load. Cytokine 73, 169-175. doi: 10.1016/j.cyto.2015.02.003

Zúñiga, L. A., Jain, R., Haines, C., and Cua, D. J. (2013). Th17 cell development: from the cradle to the grave. Immunol. Rev. 252, 78-88. doi: 10.1111/imr.12036

Conflict of Interest: The authors declare that the research was conducted in the absence of any commercial or financial relationships that could be construed as a potential conflict of interest.

Copyright (c) $2021 \mathrm{Li}$, Liu and Wang. This is an open-access article distributed under the terms of the Creative Commons Attribution License (CC BY). The use, distribution or reproduction in other forums is permitted, provided the original author(s) and the copyright owner(s) are credited and that the original publication in this journal is cited, in accordance with accepted academic practice. No use, distribution or reproduction is permitted which does not comply with these terms. 